\title{
The first report to record the parasitoids of the fall armyworm, Spodoptera frugiperda in Egypt
}

\author{
Youssef, M.A.M.
}

Field Crop Pests Department, Plant Protection Research Institute, Agricultural Research Center.

\begin{abstract}
The fall armyworm, Spodoptera frugiperda (J.E. Smith) (Lepidoptera: Noctuidae), is a harmful pest of many plants. In Egypt, the presence of $S$. frugiperda in maize fields was reported in 2019. The aim of this study was to record the parasitoids of S. frugiperda in Egypt. The survey was conducted at Sohag and Qena governorates. Survey studies showed five parasitoids were recorded. In Sohag governorate, from the total samples of fall armyworm collected, four species of parasitoids emerged, three of them belonged to order hymenoptera and one belonged to diptera. Two of the hymenopteran parasitoids were found in samples collected from Shandaweel district, Dinarmus basalis (Rondani, 1877) family Pteromalidae and Cotesia ruficrus (Haliday) family Braconidae. While the third is Microplitis rufiventris (Kokujev) family Braconidae was emerged from samples collected from ElOsyrat district. However, the dipteran parasitoid is Exorista (Tachina) larvarum (Linnaeus), which emerged from samples collected from Shandaweel district. In Qena governorate, one parasitoid species emerged Chelonus intermedius (Thomson) which was found in Abu Tesht district. Up to my knowledge this is the first record of the mentioned parasitoids on S. frugiperda in Egypt.
\end{abstract}

Keywords: Spodoptera frugiperda; Hymenoptera; Diptera; parasitoid; Survey; Egypt.

\section{Introduction}

The fall armyworm (FAW), Spodoptera frugiperda (J.E. Smith) (Lepidoptera: Noctuidae), is a harmful pest of many plants, among them corn, sorghum, cotton, and many kinds of grasses. It is distributed throughout North and South America (Sparks, 1979). Larvae of (FAW) had a wide range of hosts, in Brazil about 274 taxa of host plants are recorded. An additional 82 new host plant species were identified (Montezano et al., 2018). The invasive pest $S$. frugiperda had

\footnotetext{
*Corresponding author: Mohamed A.M. Youssef

Email: youssef44ag@gmail.com

Received: March 2, 2021;

Accepted: March 26, 2021;

Published: April 8, 2021.
}

recorded in Africa for the first time in 2016 (Goergen et al., 2016). However, in Egypt, the ministry of agriculture announced the presence of $S$. frugiperda in 2019 on maize plants in Aswan governorate (Dahi et al., 2020). Using pesticides to control $S$. frugiperda is a usual work, using various insecticides and repeating the use of it in agricultural pest control, causes a lot of hazards. So, researchers seek to found alternatives to chemical control of insect pests helping to preserve health, wildlife, environment, and for economic concerns (Mattson et al., 2000). Biological control strategies could be used to control $S$. frugiperda in integrated pest management program. Knowledge of species of natural biological control agents in native areas is necessary to make integrated management programs. Because of the efficiency and 
specificity in relation to the host, parasitoids consider one of the most important components of biological control of $S$. frugiperda. (Silva et al., 2014). In these considerations, the present study aimed to record the parasitoids of $S$. frugiperda in Egypt.

\section{Materials and Methods}

A survey of native parasitoids of $S$. frugiperda was conducted from April-October 2020 in Sohag and Qena governorates, Egypt. To conduct this survey, samples of $S$. frugiperda larvae were collected from both governorates throughout summer season. Samples were taken from three districts of Sohag governorate i.e. El-Osyrat, Saqulta and Shandaweel and two districts of Qena governorate i.e. Nag-Hamadi and Abu Tesht. In each sample, a different $S$. frugiperda larvae instars were collected. The number of $S$. frugiperda larvae gathered and the number of plants inspected differed among fields. The larvae were gathered from plants of corn, sorghum and pearl millet, every larva placed into glass flasks of 4.6 x $10.0 \mathrm{~cm}$, covered with fine gauze to prevent parasitoids to go through it. The larvae were fed under laboratory conditions with pieces of young corn plants and corn pieces replaced daily till pupation or until parasitoid emergence. The parasitoids that recovered from each larva were recorded daily. and preserved in $75 \%$ ethyl alcohol. Parasitoids were identified by the department of insect taxonomy and surveying in the Plant Protection Research Institute, Agricultural Research Center, Egypt.

\section{Results and Discussions}

Shown in table (1), in Sohag governorate from the total samples of fall armyworm collected, four species of parasitoids were emerged, three of them belonged to order hymenoptera and one belonged to order diptera. Two of the hymenopteran parasitoids were found in samples collected from Shandaweel district, Dinarmus basalis (Rondani, 1877) family Pteromalidae (Fig.1) and Cotesia ruficrus (Haliday) family Braconidae (Fig.2). While, the third is Microplitis rufiventris (Kokujev) family Braconidae (Fig.3) was emerged from samples collected from El-Osyrat district. However, the dipteran parasitoid is Exorista (Tachina) larvarum (Linnaeus) family Tachinidae (Fig.4), which emerged from samples collected from Shandaweel district. In Qena governorate from the total samples of fall armyworm larvae collected, one parasitoid species was emerged, Chelonus intermedius (Thomson) family Braconidae (Fig.5) which was found in $\mathrm{Abu}$ Tesht district and no parasitoids emerged from the samples collected from Nag-Hamadi district.

Table (1). A partial taxonomic list of parasitoids of S. frugiperda in Egypt.

\begin{tabular}{l|l|l}
\hline \multicolumn{1}{c|}{ Order } & \multicolumn{1}{c|}{ Family } & \multicolumn{1}{c}{ Scientific name } \\
\hline Hymenoptera & Pteromalidae & Dinarmus basalis \\
\cline { 2 - 3 } & & Cotesia ruficrus \\
& Braconidae & Microplitis rufiventris \\
& & Chelonus intermedius \\
\hline Diptera & Tachinidae & Exorista (Tachina) larvarum \\
\hline
\end{tabular}


Table (2). Governorate, districts, crops, parasitoids and percent of $S$. frugiperda larvae parasitized by hymenopteran and dipteran parasitoids in Egypt.

\begin{tabular}{|c|c|c|c|c|c|c|c|c|}
\hline \multirow[t]{2}{*}{ Gov. } & \multirow[t]{2}{*}{ Districts } & \multirow[t]{2}{*}{ Crop } & \multirow{2}{*}{$\begin{array}{c}\text { No. of larvae } \\
\text { Collected }\end{array}$} & \multicolumn{5}{|c|}{ \% of parasitism for each parasitoid } \\
\hline & & & & $\begin{array}{c}C . \\
\text { intermedius }\end{array}$ & $\begin{array}{c}\text { M. } \\
\text { rufiventris }\end{array}$ & $\begin{array}{c}\text { D. } \\
\text { basalis }\end{array}$ & $\begin{array}{c}E . \\
\text { larvarum }\end{array}$ & $\begin{array}{c}C . \\
\text { ruficrus }\end{array}$ \\
\hline \multirow[t]{3}{*}{ Sohag } & El-Osyrat & Maize & 108 & 0.00 & 7.40 & 0.00 & 0.00 & 0.00 \\
\hline & Shandaweel & $\begin{array}{c}\text { Maize } \\
\text { Sorghum } \\
\text { Pearl Millet }\end{array}$ & 81 & 0.00 & 0.00 & 4.94 & 1.23 & 1.23 \\
\hline & Saqulta & Maize & 16 & 0.00 & 0.00 & 0.00 & 0.00 & 0.00 \\
\hline \multirow[t]{2}{*}{ Qena } & Nag-Hamadi & Maize & 50 & 0.00 & 0.00 & 0.00 & 0.00 & 0.00 \\
\hline & Abu Tesht & Maize & 182 & 31.32 & 0.00 & 0.00 & 0.00 & 0.00 \\
\hline
\end{tabular}

According to the percent of parasitism of each of the five collected parasitoids (Table 2), the most prevalent one was $C$. intermedius (31.32), followed by $M$. rufiventris (7.40) and D. basalis (4.94). However, C. ruficrus and $E$. larvarum were the least in percent of parasitism, they recorded $1.32 \%$ of parasitism for both of them. Up to my knowledge this is the first report of the mentioned parasitoids on S. frugiperda in Egypt.

Researchers have conducted many studies on surveying parasitoids of $S$. frugiperda and other lepidopteran pests in Egypt and other parts of the world, there was a partial agreement between their studies and the current study.

In Egypt, Hegazi et al., (1977) surveyed the parasitoids of Spodoptera littoralis which belonged to the same genus of $S$. frugiperda. They found that five species were found to parasitize the immature stages of $S$. littoralis in cotton fields. These apparently all attacked the larvae and comprised Chelonus inanitus (L.), M. rufiventris Kok., Zele chlorophthalma (Nees), Euplectrus laphygmae Ferriere and Peribaea orbata (Wied.) (Strobliomyia orbata). However, in turkey, Sertkaya et al., (2004) found that the parasitoids attack Spodoptera exigua are $M$. rufiventris, $M$. tuberculifer, Chelonus obscuratus, Meteorus ictericus Nees, A. ruficrus (Haliday); Sinophorus xanthostomus and Hyposoter didymator. Ruiz-Najera et al., (2007) recorded the parasitoids of $S$. frugiperda larvae which were Rogas vaughani Muesebeck, $R$. laphygmae Viereck, Chelonus insularis Cresson, C. cautus Cresson, Glyptapanteles militaris Walsh, Neotheronia sp., Ophion flavidus Brulle, Euplectrus plathypenae Howard, Archytas marmoratus Towsend, Lespesia archippivora Riley, Archytas sp., and Winthemia sp. Megaselia scalaris. Delvare and Rasplus, (2014) recorded a new genus of pteromalid, Spodophagus lepidopterae on $S$. littoralis.

Another study in Egypt on genus of Spodoptera conducted by El-Husseini et al., (2018) who recorded the main parasitoid species of $S$. littoralis, i.e. the braconid parasitoids, $C$. inanitus (L.), A. ruficrus (Haliday), and $M$. rufiventris Kok.; the ichneumonid Z. chlorophthalma (Nees); and the tachinids Exorista larvarum (L.) and Strobliomyia aegyptia Vill., recovered from $S$. littoralis larvae and pupae, four of the previous parasitoids were recorded on $S$. frugiperda in the current study. Shylesha et al., (2018) in India and Malaysia, found that Glyptapanteles creatonoti, is an important parasitoid of many lepidopterous pest and can parasitize in S. frugiperda. 


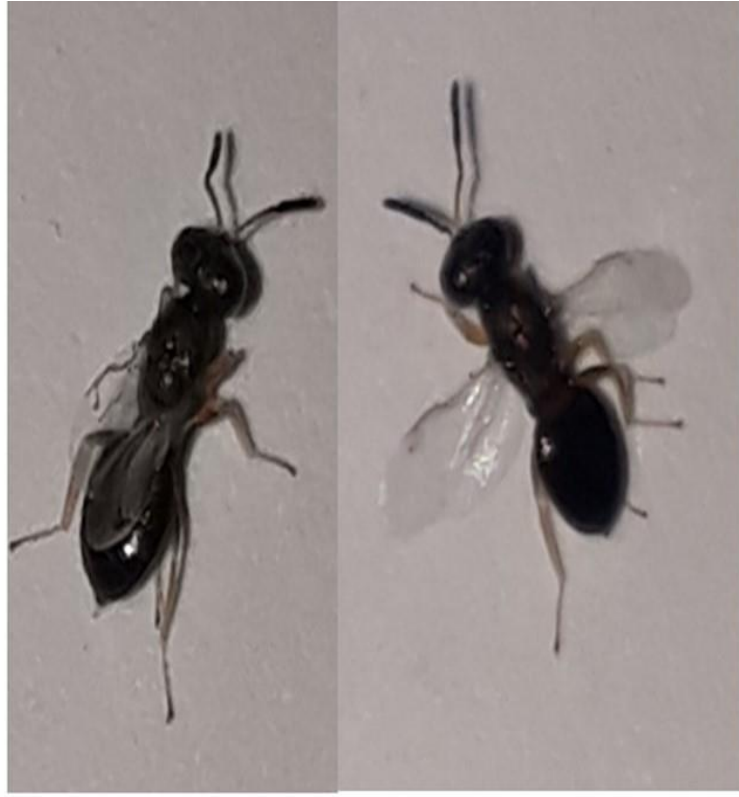

Figure 1: $D$. basalis parasitoid

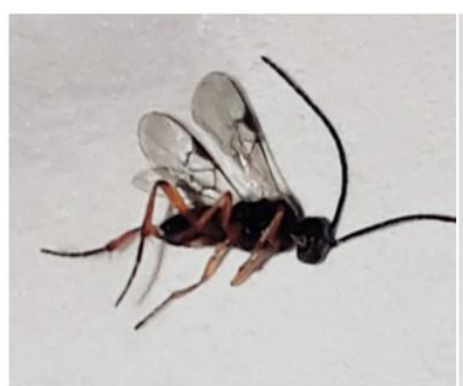

Figure 2 a: C. ruficrus parasitoid adult

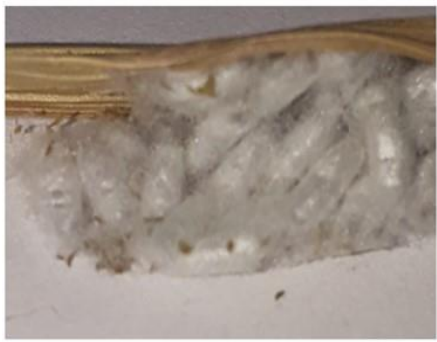

Figure $2 \mathrm{~b}$ : $\mathrm{C}$. ruficrus cocoons

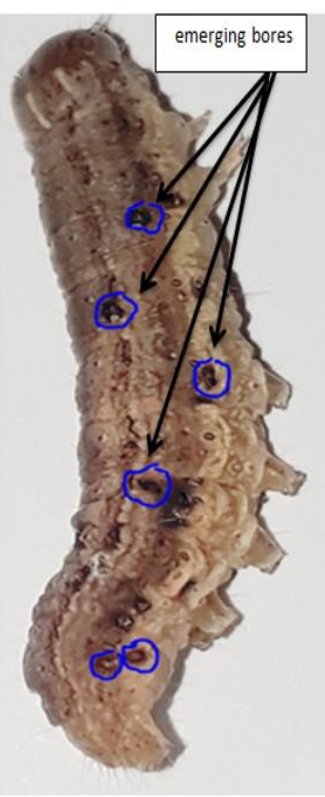

Figure $2 \mathrm{c}$ : emerging bores of $C$.

ruficrus parasitoid on $S$.

frugiperda larvae

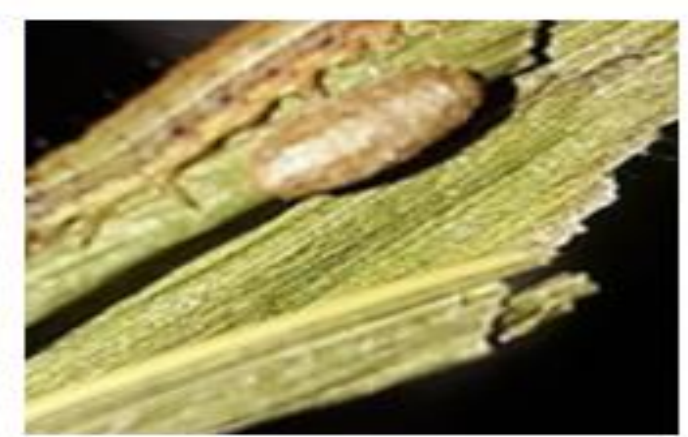

Figure 3 a: M.rufiventris parasitoid cocoon beside $S$. frugiperda larvae

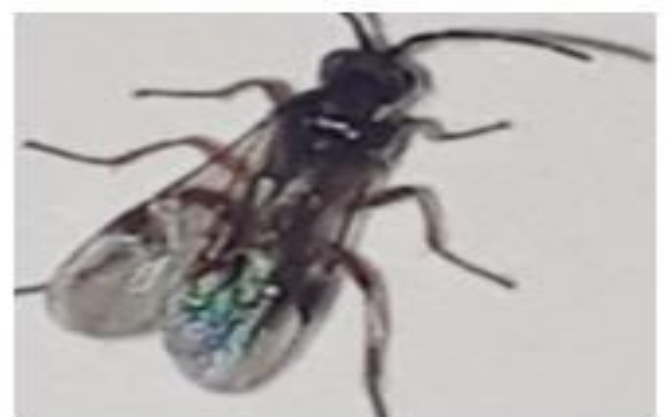

Figure 3 b: M.rufiventris parasitoid adult

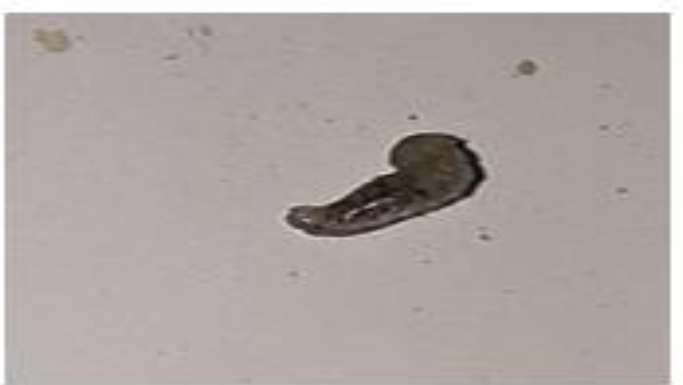

Figure 3 c: M.rufiventris larvae

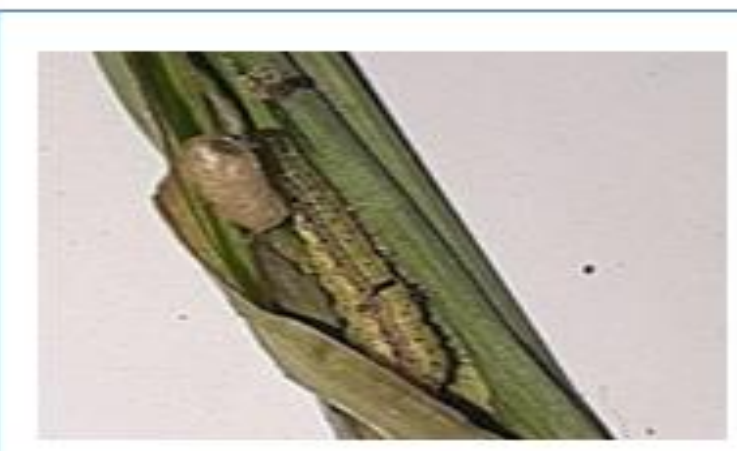

Figure $\mathbf{3}$ d: M.rufiventris cocoon after adult emerged 


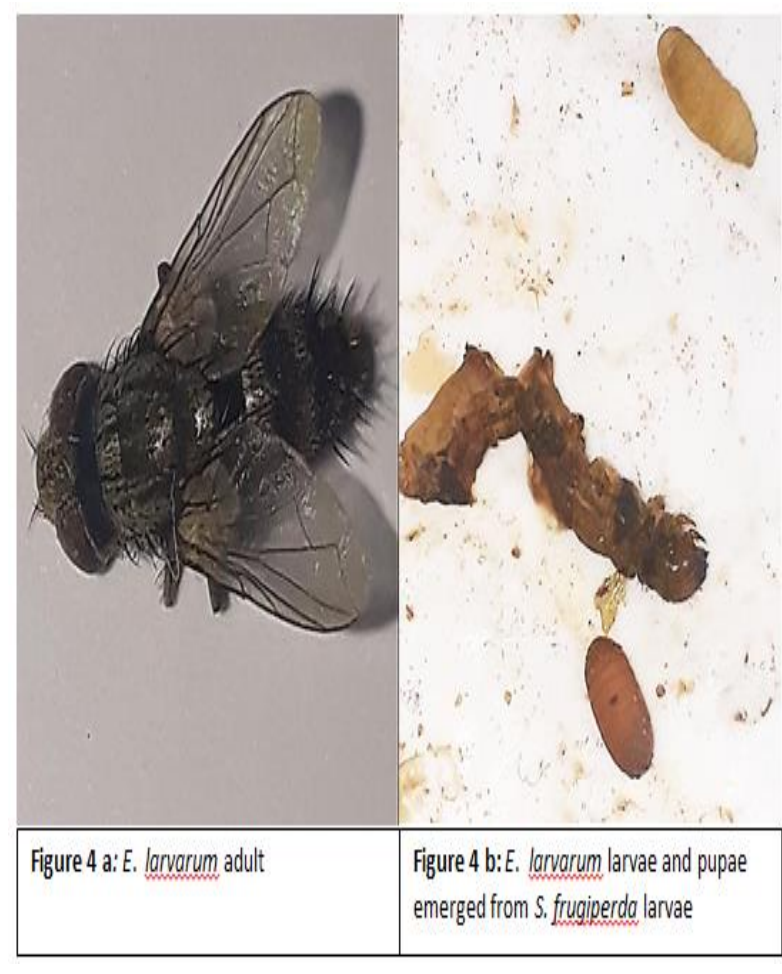

In Ghana and Benin, a survey of S. frugiperda parasitoids was conducted by Agboyi et al. (2020) they recorded ten parasitoids. They found that the most abundant parasitoids were Chelonus bifoveolatus and Coccygidum luteum. Caniço et al., (2020) recorded five larval parasitoids for the invasive insect pest $S$. frugiperda. Koffi et al., (2020) recorded natural enemies of $S$. frugiperda. They mentioned that among the natural enemies, 7 species were parasitoids: Coccygidium luteum (Brull),Chelonus bifoveolatus Szpligeti, $C$. icipe Fernandez, Bracon sp. and Meteoridea testacea (Granger). All of them are hymenopteran. Also, they recorded two Dipteran parasitoids on of them is Anatrichus erinaceus Loew and the other is an identified. Navik et al., (2020) in India, recorded the tachinid fly, Exorista xanthaspis for the first time parasitize the larvae of $S$. frugiperda collected from corn plants.

\section{References}

Agboyi, L.K., Goergen, G., Beseh, P., Mensah, S.A., Clottey, V.A., Glikpo, R., Buddie, A.,

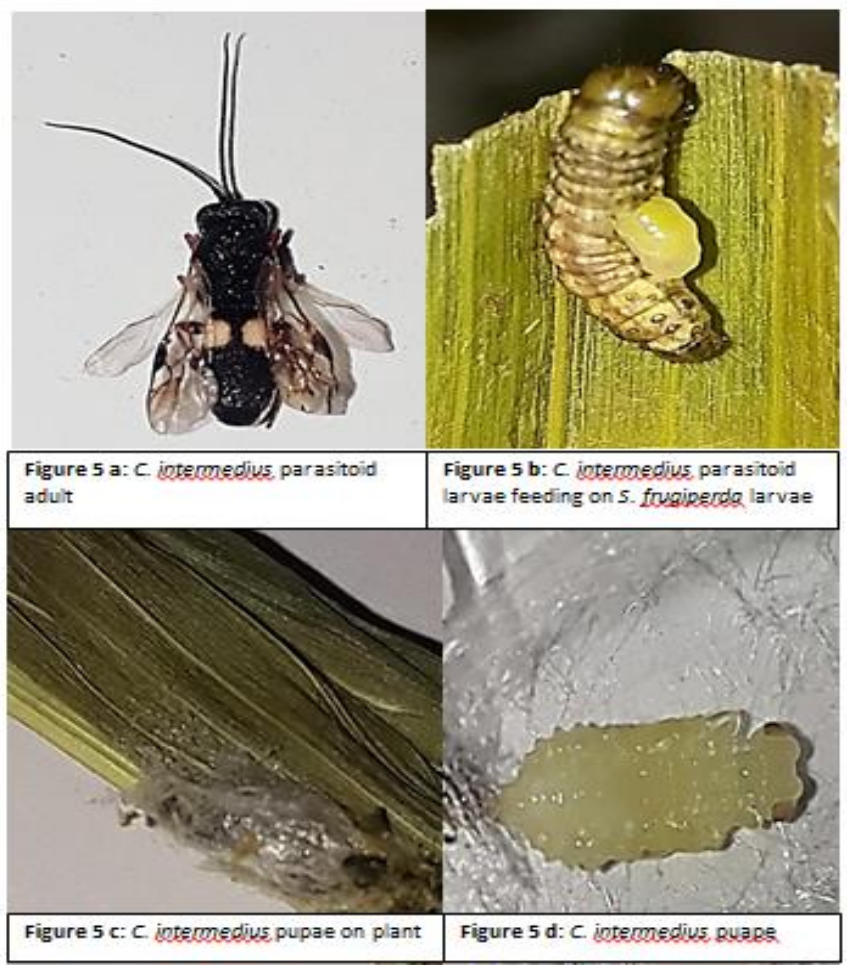

Cafà, G., Offord, Lisa, D.R., Rwomushana, I. and Kenis, M. (2020) 'Parasitoid complex of fall armyworm Spodoptera frugiperda, in Ghana and Benin' Insects 11(68), pp. 15.

Caniço, A., Mexia, A. and Santos, Luisa (2020) 'First report of native Parasitoids of fall armyworm Spodoptera frugiperda Smith (Lepidoptera: Noctuidae) in Mozambique' Insects, 11(615), pp. 1-12.

Dahi, H.F., Salem, S.A.R., Gamil, W.E. and Mohamed, H.O. (2020) 'Heat Requirements for the Fall Armyworm Spodoptera frugiperda (J. E. Smith) (Lepidoptera: Noctuidae) as a New Invasive Pest in Egypt' Egypt. Acad. J. Biolog. Sci., 13(4), pp. 73-85.

Delvare, G. and Rasplus, J.Y. (2014) 'Spodophagus, a new genus of Pteromalidae (Hymenoptera), for an important parasite of Spodoptera littoralis (Lepidoptera: Noctuidae) in Madagascar' Bulletin of Entomological Research 84, pp. 191-197.

El-Husseini, M.M., El-Heneidy, A.H. and Awadallah, K.T. (2018) 'Natural enemies associated with some economic pests in Egyptian agro-ecosystems' Egypt. J. biol. pest control 28(78), pp. 571-587. 
Goergen, G., Kumar, P.L., Sankung, S.B., Togola, A. and Tamo, M. (2016) 'First report of outbreaks of the fall armyworm Spodoptera frugiperda (J. E. Smith) (Lepidoptera, Noctuidae), a new alien invasive pest in West and Central Africa' PLoS ONE 11(10), e0165632.

doi:10.1371/journal.pone.0165632.

Hegazi, E.M., Hammad, S.M. and El-Minshawy, A.M. (1977) 'Field and laboratory observations on the parasitoids of Spodoptera littoralis (Boisd.) (Lep.: Noctuidae) in Alexandria' Zeitschrift fur Angewandte Entomologie, 84(3), pp. 316-321.

Koffi, D., Kyerematen, R., Eziah, V.Y., Agboka, K., Adom, M., Goergen, G. and Meagher, R.L. (2020) 'Natural enemies of the fall armyworm, Spodoptera frugiperda (J.E. Smith) (Lepidoptera: Noctuidae) in Ghana' Florida Entomologist 103 (1), pp. 85-90.

Mattson, J.L., Maurissen, J.P.J., Nolan, R.J. and Brzak, K.A. (2000) 'Lack of differential sensitivity to cholinesterase inhibition in fetuses and neonates compared to dams treated perinatally with chlorpyrifos' Toxicological Sci. 53, pp. 438-446.

Montezano D.G., Sosa-Gómez, D.R., RoqueSpecht, V.F., Sousa-Silva, J.C., PaulaMoraes, S.V., Peterson, J.A. and Hunt, T.E. (2018) 'Host plants of Spodoptera frugiperda (Lepidoptera: Noctuidae) in the Americas' African Entomology. 26(2), pp. 286-300.

Navik, O., Venkatesan, T. and Ashika, T.R. (2020) 'First report of Exorista xanthaspis (Wiedemann, 1830) (Diptera: Tachinidae), a larval-pupal parasitoid on invasive pest, Spodoptera frugiperda (J. E. Smith) in maize from India' Journal of Biological Control, 34(1), pp. 82-85.

Ruiz-Najera, R.E., Molina-Ochoa, J., Carpenter, J.E., Espinosa-Moreno, J.A., Ruiz-Najera, J.A., Lezama-Gutierrez, R. and Foster, J.E. (2007) 'Survey for Hymenopteran and Dipteran Parasitoids of the Fall Armyworm (Lepidoptera: Noctuidae) in Chiapas, Mexico' J. Agric. Urban Entomol. 24(1), pp. 35-42.
Sertkaya, E., Bayram, A. and Kornosor, S. (2004) 'Egg and Larval Parasitoids of the Beet Armyworm Spodoptera exigua on Maize in Turkey' Phytoparasitica 32(3), 305-312.

Shylesha, A.N., Jalali, S.K., Gupta A., Varshney, R., Venkatesan, T., Shetty, P., Ojha, R., Ganiger, P.C., Navik, O., Subaharan, K., Bakthavatsalam, N. and Ballal, C.R. (2018) 'Studies on new invasive pest Spodoptera frugiperda (J. E. Smith) (Lepidoptera: Noctuidae) and its natural enemies' Journal of Biological Control, 32(3), pp. 1-7.

Silva, R.B., Cruz, I. and Penteado-Dias, A.M. (2014) 'First report of Dolichozele koebelei Viereck, 1911 (Hymenoptera: Braconidae) on larvae of Spodoptera frugiperda (J. E. Smith, 1797) (Lepidoptera: Noctuidae) in maize (Zea mays L.) under different cropping systems' Braz. J. Biol., 74 (3), pp. 218-222.

Sisay, B., Simiyu, Josephine, Malusi, P., Likhayo, P., Mendesil, E., Elibariki, N., Wakgari, M., Ayalew, G. and Tefera, T. (2018) 'First report of the fall armyworm, Spodoptera frugiperda (Lepidoptera: Noctuidae), natural enemies from Africa' J. Appl. Entomol. 142, pp. 800804.

Sparks, A. (1979) 'A review of the biology of the fall armyworm' Florida Entomologist 62, pp. 282-287.

Tendeng, E., Labou, B., Diatte, M., Djiba, S. and Diarra, K. (2019) 'The fall armyworm Spodoptera frugiperda (J.E. Smith), a new pest of maize in Africa: biology and first native natural enemies detected' Int. J. Biol. Chem. Sci. 13(2), pp. 1011-1026. 